\title{
Uptake and Utilization of Trans Octadecenoic Acids in Lactating Dairy Cows ${ }^{1}$
}

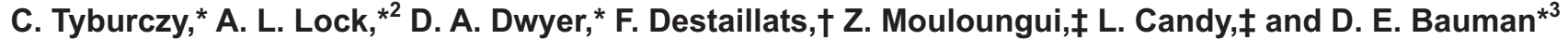 \\ *Department of Animal Science, Cornell University, Ithaca, NY 14853 \\ †Nestle Research Center, Vers-chez-les-Blanc, 1000 Lausanne, Switzerland \\ fLaboratoire de Chimie Agro-Industrielle, Unité Mixte de Recherche 1010, Institut National de la Recherche Agronomique/Institut National \\ Polytechnique de Toulouse-Ecole Nationale Supérieure des Ingénieurs en Arts Chimiques et Technologiques, 31077 Toulouse, France
}

\section{ABSTRACT}

Trans fatty acids (FA) arise in ruminant-derived foods as a consequence of rumen biohydrogenation and are of interest because of their biological effects and potential role in chronic human diseases. Our objective was to compare 2 trans FA, elaidic acid (EA; trans-9 18:1) and vaccenic acid (VA; trans-11 18:1), with oleic acid (OA; cis-9 18:1) relative to plasma lipid transport and mammary utilization for milk fat synthesis. Three ruminally cannulated, Holstein dairy cows, $259 \pm 6$ $\mathrm{DIM}$ (mean $\pm \mathrm{SEM}$ ), were randomly assigned in a $3 \times 3$ Latin square design. Treatments were a 4 -d abomasal infusion of 1) OA (45.5 g/d), 2) EA (41.7 g/d), and 3) VA $(41.4 \mathrm{~g} / \mathrm{d})$. Milk samples were collected at each milking and blood samples were collected at the start and end of each treatment period. The proportions of total plasma FA associated with each plasma lipid fraction at baseline (pretreatment) were $62.6 \pm 0.6 \%$ phospholipids, $26.1 \pm 0.6 \%$ cholesterol esters, $9.8 \pm 0.4 \%$ triglycerides, and $1.5 \pm 0.1 \%$ nonesterified fatty acids; these values were unaffected by treatment. There were striking differences in the FA composition of the individual plasma lipid fractions and in the distribution of specific 18-carbon FA among the lipid fractions. Infusion of treatment isomers caused their specific increase in the various plasma lipid fractions but had no effect on milk production variables, including milk fat yield and content. Transfer efficiency of infused OA, EA, and VA to milk fat averaged $65.5 \pm 3.0 \%, 59.7 \pm 1.5 \%$, and 54.3 $\pm 0.6 \%$, respectively. For the VA infusion, $24.6 \pm 1.1 \%$ of the transfer was accounted for by the increased yield of cis-9, trans-11 conjugated linoleic acid in milk fat,

\footnotetext{
Received November 26, 2007.

Accepted June 22, 2008.

${ }^{1}$ Supported by the Cornell Agricultural Experiment Station and the Nestle Research Center. Also supported in part by the Cooperative State Research, Education, and Extension Service, USDA, under Agreement No. NYC-127437. Any opinions, findings, conclusions or recommendations expressed in this publication are those of the authors and do not necessarily reflect the view of the USDA.

${ }^{2}$ Current address: Department of Animal Science, University of Vermont, Burlington 05405.

${ }^{3}$ Corresponding author: deb6@cornell.edu
}

consistent with its endogenous synthesis from VA via the mammary enzyme $\Delta^{9}$-desaturase. Notably, linoleic acid (18:2n-6) and linolenic acid (18:3n-3) accounted for $47.7 \%$ of total plasma FA, but only $2.6 \%$ of FA in milk. Overall, results demonstrate clear differences in plasma transport and mammary uptake and utilization of 18-carbon FA, and these relate to the location, orientation, and number of double bonds.

Key words: milk fat, lactation, plasma lipid, trans fatty acid

\section{INTRODUCTION}

As consumers are becoming aware of the links between dietary fat, health maintenance, and disease prevention, there is an increasing need for clarification of the metabolic fate and bioactivity of dietary fatty acids (FA). When considering milk and dairy products, we are particularly concerned with the content of saturated and unsaturated FA, bioactive FA (e.g., conjugated linoleic acid and n-3 FA), and trans FA (Lock and Bauman, 2004). The current interest in trans FA with regard to milk fat is 2 -fold. In relation to human health, trans FA have been associated with increased risk of chronic diseases, including cardiovascular disease, systemic inflammation, and type-II diabetes (Willett, 2006). With respect to milk fat depression (MFD), an inverse association is typically observed between the milk fat content of trans 18:1 isomers and the extent of the reduction in milk fat yield or content (Bauman and Griinari, 2003).

Factors affecting the FA composition of milk fat include the extent of de novo lipid synthesis by the mammary gland, the supply of preformed FA arising from dietary lipid intake and ruminal biohydrogenation of polyunsaturated FA (PUFA), and also the plasma transport of FA and their selective uptake and utilization by the mammary gland. Transport of FA in the bloodstream is complex and involves various plasma lipid fractions, including phospholipids (PL), cholesterol esters (CE), triglycerides (TG), and NEFA. With regard to milk fat synthesis, the mammary gland preferentially utilizes FA from the plasma TG and 
NEFA fractions, and uptake is proportional to their concentration (Moore and Christie, 1979). In contrast, comparisons of the FA composition of bovine plasma and milk lipids indicate that some FA are distributed to plasma lipid fractions (e.g., PL and CE) that are less well utilized as a source of FA for mammary uptake (Moore and Christie, 1979).

The metabolism of octadecenoic acids is largely influenced by the location and orientation of the double bond (Allison et al., 1995). In terms of the plasma transport of trans 18:1 FA, Loor et al. (2002) demonstrated that as a proportion of FA within a lipid fraction, vaccenic acid (VA) was greatest in plasma TG, whereas Mosley et al. (2006) found that across all fractions, the greatest concentration of VA was in plasma PL. These analyses have not been reported for other trans 18:1 isomers in the plasma of lactating dairy cows. We hypothesize that differences in the physical structure between cis and trans double bonds may affect the distribution of octadecenoic acids among plasma lipid fractions, and this would subsequently affect the uptake and use of individual isomers for mammary synthesis of milk fat. Thus, our objective was to compare 2 trans octadecenoic acids, trans-9 18:1 (elaidic acid; EA) and trans-11 18:1 (VA), with cis-9 18:1 (oleic acid, OA), in terms of plasma lipid transport and utilization by the mammary gland for milk fat synthesis. Trans FA have also been implicated in diet-induced MFD (Bauman and Griinari, 2003), and our investigation offered a unique opportunity to observe the effects of EA and VA on the regulation of milk fat synthesis.

\section{MATERIALS AND METHODS}

\section{Animals and Experimental Methods}

All procedures involving animals were approved by the Cornell University Institutional Animal Care and Use Committee. Three ruminally cannulated Holstein dairy cows, $259 \pm 6$ DIM (mean \pm SEM), were randomly assigned in a $3 \times 3$ Latin square design. Before the start of the first treatment period, cows were fitted with abomasal infusion lines $(0.5-\mathrm{cm}$ i.d. polyvinyl chloride tubing) passing through the rumen fistula and sulcus omasi (Lock et al., 2007). Lines were checked daily during treatment periods to ensure that infused isomers were properly delivered into the abomasum. Treatments were FFA of 1) OA (45.5 g/d), 2) EA (41.7 $\mathrm{g} / \mathrm{d})$, and 3) VA (41.4 g/d) solubilized in $95 \%$ ethanol and heated to $37^{\circ} \mathrm{C}$ before infusion. Infusions provided approximately $45 \mathrm{~mL} / \mathrm{d}$ of ethanol, and equal amounts of infusate mixture were abomasally infused 6 times/d. Treatment periods were $4 \mathrm{~d}$, with a 7 -d washout interval between treatments.
Cows consumed a corn silage-based diet (Table 1) formulated by using the Cornell Net Carbohydrate and Protein System (Fox et al., 2004) to meet or exceed nutrient requirements for energy, protein, minerals, and vitamins (NRC, 2001), and had free access to water at all times. Cows were fed ad libitum with fresh feed offered twice daily at 1100 and $1800 \mathrm{~h}$, and orts were determined daily. Feed samples were collected twice during each treatment period, and composites were formed and analyzed by wet chemistry procedures for $\mathrm{CP}, \mathrm{ADF}, \mathrm{NDF}$, and ether extract (Dairy One Cooperative Inc., Ithaca, NY).

\section{Synthesis and Characterization of Fatty Acid Supplements}

Three octadecenoic acid supplements were used in this investigation. The OA supplement was purchased from Sigma-Aldrich (St. Louis, MO). The EA and VA supplements were synthesized and purified by proprietary procedures based on methods that are referenced in Lock et al. (2007). During the synthesis and purification processes, the EA and VA products were characterized by several different procedures, including GC, melting point determinations, infrared spectroscopy, and ${ }^{1} \mathrm{H}$ and ${ }^{13} \mathrm{C}$ nuclear magnetic resonance spectral analysis (Lock et al., 2007). The EA product (83\% purity) was a yellow solid, melting at 42 to $43^{\circ} \mathrm{C}$; the VA product ( $83 \%$ purity) was similar in appearance and melted at 45 to $46^{\circ} \mathrm{C}$.

\section{Experimental Procedures and Analysis}

Cows were housed in individual tie stalls at the Large Animal Research and Teaching Unit in Ithaca, New York. Cows were milked twice daily at 0700 and $1900 \mathrm{~h}$, and 2 aliquots of milk were collected at each milking. One aliquot was stored with preservative (bronopol tablet; D \& F Control Systems Inc., San Ramon, CA) at $4^{\circ} \mathrm{C}$ until infrared analysis was performed for fat, true protein, lactose, and somatic cells (Dairy One Cooperative Inc.) as described by Bernal-Santos et al. (2003). A second aliquot was stored without preservative at $-20^{\circ} \mathrm{C}$ until $\mathrm{FA}$ analysis was performed.

Milk lipids were extracted according to Hara and Radin (1978) by using hexane:isopropanol (3:2) and sodium sulfate, and were transmethylated by using sodium methoxide according to the method of Christie (1982), with modifications by Chouinard et al. (1999). Fatty acid methyl esters were quantified as described by Perfield et al. (2002), which involved a GC system (GCD system HP 6890+, Hewlett-Packard, Avondale, PA) equipped with a CP-Sil 88 fused-silica capillary column $(100 \mathrm{~m} \times 0.25 \mathrm{~mm}$ i.d., with $0.2 \mu \mathrm{m}$ film thick- 
Table 1. Ingredient and chemical composition of diet

\begin{tabular}{lc}
\hline Composition & Content \\
\hline Dietary ingredient, \% of DM $^{1}$ & \\
Corn silage $^{1}$ & 31.4 \\
Alfalfa silage $^{2}$ & 24.0 \\
Straw & 1.0 \\
High-moisture corn & 9.6 \\
Ground corn & 10.6 \\
Grain mix, 23.4\% DM & \\
Corn gluten feed & 7.7 \\
Corn distillers grains & 6.9 \\
Wheat middlings & 4.0 \\
Limestone & 1.2 \\
Blood meal & 0.7 \\
Sodium bicarbonate & 0.6 \\
Tallow & 0.4 \\
Urea & 0.4 \\
Salt & 0.4 \\
Corn gluten meal & 0.4 \\
Calcium sulfate & 0.2 \\
Citrus pulp & 0.1 \\
Magnesium oxide & 0.1 \\
Selenium blend & \\
Trace mineral mixture & 4 \\
Vitamin ADE mixture & 0.04 \\
Mepron & \\
Vitamin E & 0.04 \\
Chemical analysis, \% of DM & 0.02 \\
NDF & 0.01 \\
ADF & 0.005 \\
CP & \\
Ether extract & 34.2 \\
NE ${ }^{8}$ MJ/kg of DM & 22.6 \\
1 Co & 16.8 \\
& 4.8 \\
Dala & 6.9 \\
\hline
\end{tabular}

${ }^{1}$ Corn silage contained $30.0 \% \mathrm{DM}$ (as fed).

${ }^{2}$ Alfalfa silage contained 29.6\% DM (as fed).

${ }^{3}$ Selenium blend contained $0.06 \%$ sodium selenite.

${ }^{4}$ Trace mineral mixture contained (g/100 g): 12.3 calcium, 12.5 sulfur, 0.32 magnesium, 1.9 copper, 9.0 magnesium, 0.25 cobalt, 0.19 iodine, and 11.0 zinc.

${ }^{5}$ Vitamin ADE mixture contained (g/kg) 10.8 retinyl acetate, 0.18 cholecalciferol, and 0.047 DL-a-tocopherol.

${ }^{6}$ Rumen-protected methionine; Evonik Industries AG, Essen, Germany.

${ }^{7}$ Vitamin E contained $69.1 \mathrm{~g} / \mathrm{kg}$ of DL-a-tocopherol.

${ }^{8}$ Net energy for lactation.

ness; Varian Inc., Walnut Creek, CA). Fatty acid peaks were identified by using pure methyl ester standards (Nu-Chek Prep Inc., Elysian, MN), and a butter oil reference standard (CRM 164; Commission of the European Community Bureau of References, Brussels, Belgium) was used for routine quality control and internal correction factors. This same GC analysis was used for the final characterization of the octadecenoic acid supplements (Table 2).

Blood samples (approximately $30 \mathrm{~mL}$ ) were collected by coccygeal venipuncture into Vacutainer tubes containing sodium heparin $(100 \mathrm{U} / \mathrm{mL}$ of blood; Becton Dickinson, Franklin Lakes, NJ) at the start and end of each treatment period. Plasma was harvested by centrifuging blood at $2,300 \times \mathrm{g}$ for $15 \mathrm{~min}$ at $4^{\circ} \mathrm{C}$, and was stored at $-20^{\circ} \mathrm{C}$ until analyzed for lipids. Total plasma
Table 2. Fatty acid composition of infusates ${ }^{1}$

\begin{tabular}{lrrr}
\hline & \multicolumn{3}{c}{ Infusate $^{2}$} \\
\cline { 2 - 4 } Fatty acid, g/100 g & OA & EA & VA \\
\hline $16: 0$ & 0.3 & 2.6 & 2.6 \\
$18: 0$ & 2.4 & 3.2 & 3.2 \\
$18: 1$, trans-9 & 2.9 & 83.4 & 0.0 \\
$18: 1$, trans-11 & 0.0 & 0.0 & 82.8 \\
$18: 1$, cis-9 & 91.0 & 8.9 & 8.9 \\
$18: 2 \mathrm{n}-6$ & 2.6 & 0.0 & 0.0 \\
Other & 0.7 & 2.0 & 2.4 \\
\hline
\end{tabular}

${ }^{1}$ Fatty acids were solubilized in $95 \%$ ethanol and equal quantities were infused into the abomasum 6 times per day.

${ }^{2} \mathrm{OA}=$ oleic acid; $\mathrm{EA}=$ elaidic acid; $\mathrm{VA}=$ vaccenic acid .

lipids were extracted according to Hara and Radin (1978) and methylated by using $2 \%$ methanolic sulfuric acid and toluene overnight at $40^{\circ} \mathrm{C}$ according to the method of Christie (1989), with modifications. Plasma lipid fractions were separated by thin-layer chromatography by using a hexane:diethyl ether:acetic acid developing solvent (80:20:2) according to the method of Christie (1989), with modifications. Briefly, extracted plasma lipids were resolubilized in chloroform, spotted on channeled silica G plates (Analtech Inc., Newark, $\mathrm{DE}$ ), and allowed to develop for approximately $45 \mathrm{~min}$ in the solvent system. Plates were sprayed with $2^{\prime}, 7^{\prime}$ dichlorofluorescein in 95\% methanol, and bands were identified under UV light against known standards for PL, cholesterol, NEFA, TG, and CE (Nu-Chek Prep Inc.). Lipid fractions were scraped from the plates, extracted by using chloroform:methanol (2:1), and methylated as described previously for total plasma lipids. For analysis of plasma FA, GC conditions were as follows: the oven temperature was initially set at $80^{\circ} \mathrm{C}$, then increased at $2^{\circ} \mathrm{C} / \mathrm{min}$ to $190^{\circ} \mathrm{C}$ and held for $20 \mathrm{~min}$, then increased at $10^{\circ} \mathrm{C} / \mathrm{min}$ to $225^{\circ} \mathrm{C}$ and held for $12 \mathrm{~min}$. The inlet and flame-ionization detector temperatures were $250^{\circ} \mathrm{C}$, the split ratio was $50: 1$, and a $4-\mu \mathrm{L}$ injection volume was used. The hydrogen carrier gas flow to the detector was $25 \mathrm{~mL} / \mathrm{min}$, airflow was $400 \mathrm{~mL} / \mathrm{min}$, and the flow of nitrogen makeup gas was $40 \mathrm{~mL} / \mathrm{min}$. Fatty acid peaks were identified by using pure methyl ester standards (Nu-Chek Prep Inc.).

Quantification of plasma lipid fractions (total cholesterol, free cholesterol, PL, TG, and NEFA) was carried out enzymatically by using commercially available kits according to the manufacturer's directions (Wako Chemicals USA Inc., Richmond, VA), and read on a Beckman DU640 spectrophotometer (Beckman Coulter Inc., Fullerton, CA). The maximum acceptable coefficient of variation was $5.0 \%$. Concentration of plasma $\mathrm{CE}$ was determined as the difference between total cholesterol and free cholesterol. 
Table 3. Performance of lactating cows during infusion periods ${ }^{1}$

\begin{tabular}{|c|c|c|c|c|c|}
\hline \multirow[b]{2}{*}{ Variable } & \multicolumn{3}{|c|}{ Fatty acid infusion ${ }^{2}$} & \multirow[b]{2}{*}{ SEM } & \multirow[b]{2}{*}{$P$-value ${ }^{3}$} \\
\hline & $\mathrm{OA}$ & EA & VA & & \\
\hline DMI, $\mathrm{kg} / \mathrm{d}$ & 19.6 & 20.0 & 19.3 & 0.60 & 0.69 \\
\hline Milk yield, kg/d & 24.3 & 24.4 & 23.5 & 1.39 & 0.77 \\
\hline \multicolumn{6}{|l|}{ Milk fat } \\
\hline$\%$ & 3.80 & 3.74 & 3.71 & 0.12 & 0.60 \\
\hline \multirow{2}{*}{\multicolumn{6}{|c|}{ Milk protein }} \\
\hline & & & & & \\
\hline$\%$ & $3.17^{\mathrm{a}}$ & $3.06^{\mathrm{b}}$ & $3.03^{\mathrm{b}}$ & 0.15 & 0.05 \\
\hline $\mathrm{kg} / \mathrm{d}$ & 0.75 & 0.74 & 0.74 & 0.04 & 0.88 \\
\hline \multicolumn{6}{|l|}{ Milk lactose } \\
\hline$\%$ & $4.72^{\mathrm{b}}$ & $4.72^{\mathrm{b}}$ & $4.76^{\mathrm{a}}$ & 0.06 & 0.03 \\
\hline $\mathrm{kg} / \mathrm{d}$ & 1.12 & 1.14 & 1.15 & 0.04 & 0.67 \\
\hline
\end{tabular}

${ }^{\mathrm{a}, \mathrm{b}}$ Means in a row without a common letter differ, $P<0.05$.

${ }^{1}$ Values represent least squares means \pm SEM $(n=3$ cows) during $d 3$ to 4 of the infusion periods.

${ }^{2}$ Abomasal infusions were oleic acid (OA; $45.5 \mathrm{~g} / \mathrm{d}$ ), elaidic acid (EA; $41.7 \mathrm{~g} / \mathrm{d}$ ), and vaccenic acid (VA; 41.4 $\mathrm{g} / \mathrm{d})$.

${ }^{3} P$-value represents the probability of a treatment effect.

\section{Calculations}

Calculations for the proportions of FA constituting individual plasma lipid fractions were based on the molecular weight and molar percentage of FA within the lipid fractions. These values were adjusted for the loss of hydrogen and oxygen during the esterification of FA to glycerol or cholesterol, and for the formation of the amide bond in sphingomyelin. The proportions of individual PL in bovine plasma have been characterized by Christie (1981), and these values were used in calculating the average FA component of plasma PL.
The method of Glasser et al. (2007) was used to calculate yields of FA in the milk fat TG by using milk fat yield, milk FA composition, and FA molecular weights. This method attributes the oxygen in the ester linkage to the esterified FA. Transfer efficiency of infused isomers to milk fat was calculated on an individual cow basis and accounted for the incremental increase in secretion of the infused isomer in milk fat. The difference between baseline secretion (pretreatment) and the average of $d 3$ and 4 secretions of infused isomers in milk fat was determined, and this was expressed as a proportion of the amount of isomer infused daily. In

Table 4. Concentration of individual plasma lipid fractions and plasma fatty acids ${ }^{1}$

\begin{tabular}{lrrrrrrr}
\hline & & \multicolumn{7}{c}{ Fatty acid infusion $^{3}$} & & & \\
\cline { 3 - 4 } Variable $^{2}$ & Baseline & \multicolumn{1}{c}{ OA } & \multicolumn{1}{c}{ EA } & VA & SEM & $P$-value $^{4}$ & $P^{\prime}$-value $^{5}$ \\
\hline Plasma lipids, mg/dL & & & & & & & \\
PL & 255.1 & 241.9 & 280.0 & 232.1 & 23.1 & 0.47 & 0.72 \\
CE & 147.2 & 157.8 & 171.2 & 155.1 & 7.7 & 0.57 & 0.01 \\
TG & 24.7 & 29.3 & 26.4 & 31.2 & 0.9 & 0.11 & 0.002 \\
NEFA & 3.7 & 3.1 & 3.0 & 2.8 & 0.3 & 0.40 & 0.08 \\
FC & 38.9 & 49.3 & 50.7 & 50.8 & 1.2 & 0.99 & $<0.001$ \\
Plasma fatty acids, mg/dL & & & & & & & \\
PL & 151.6 & 166.5 & 143.9 & 137.9 & 13.6 & 0.46 & 0.72 \\
CE & 63.0 & 67.5 & 73.4 & 66.5 & 3.2 & 0.55 & 0.01 \\
TG & 23.6 & 28.0 & 25.3 & 29.9 & 0.8 & 0.11 & 0.002 \\
NEFA & 3.7 & 3.1 & 3.0 & 2.8 & 0.3 & 0.40 & 0.08 \\
\hline
\end{tabular}

${ }^{1}$ Values represent least squares means \pm SEM $(n=3$ cows) at baseline (pretreatment) and on $d 4$ of infusion.

${ }^{2}$ Plasma lipid fractions abbreviations: $\mathrm{PL}=$ phospholipids; $\mathrm{CE}=$ cholesterol esters; $\mathrm{TG}=$ triglycerides; $\mathrm{FC}=$ free cholesterol.

${ }^{3}$ Abomasal infusions were oleic acid (OA; $45.5 \mathrm{~g} / \mathrm{d}$ ), elaidic acid (EA; $\left.41.7 \mathrm{~g} / \mathrm{d}\right)$, and vaccenic acid (VA; 41.4 $\mathrm{g} / \mathrm{d})$.

${ }^{4} P$-value represents the probability of an effect among treatments.

${ }^{5} P^{\prime}$-value represents the probability of a nonspecific treatment effect in relation to baseline values. Analyses were carried out by using matched-pairs comparisons. 
the case of VA, the transfer efficiency calculation also accounted for the incremental increase in the secretion of cis-9, trans-11 18:2 (rumenic acid; RA) in milk fat.

\section{Statistical Analysis}

Statistical analysis was carried out by using the fit model procedure of JMP (version 6.0.2, 2006, SAS Institute Inc., Cary, NC) and involved the fixed effects of treatment and period, and the random effect of cow. Period was removed from the model when considered not significant at $P>0.35$. When applicable, baseline values were used as a covariate in the model. Matchedpairs analysis was used to determine the overall effect of treatment as compared with baseline values for concentrations of individual plasma lipid fractions. Effects were declared significant at $P<0.05$.

\section{RESULTS AND DISCUSSION}

\section{Animal Performance}

Abomasal infusion is a commonly used experimental method for providing unsaturated FA to ruminant animals while bypassing alterations from rumen fermentation. In the current study, approximately 40 to $45 \mathrm{~g} / \mathrm{d}$ of OA, EA, or VA was abomasally infused in the respective treatments. The amount of infusate was selected based on isomer availability, and infusion amounts are of a magnitude similar to reported measurements of rumen outflow [see Loor et al. (2004), and the review by Palmquist et al. (2005)] and to the estimated supply in partially hydrogenated vegetable oil (PHVO) infusion studies (Gaynor et al., 1994; Romo et al., 1996). The infused isomers were provided as FFA, the form that rumen biohydrogenation intermediates and the majority of dietary-derived FA would typically pass to the small intestine in ruminants; thus, we expected a high efficiency of absorption in the small intestine (Moore and Christie, 1979).

Dry matter intake and milk yield were similar across treatments, averaging $19.6 \pm 0.3$ and $24.1 \pm 0.7 \mathrm{~kg} / \mathrm{d}$ (mean $\pm \mathrm{SEM}$ ), respectively (Table 3). Yields of milk fat, milk protein, and milk lactose were unaffected by treatment; there were small differences, however, in the content of protein and lactose in milk. Somatic cell count was unaffected by treatment, averaging $1.0 \times$ $10^{5} / \mathrm{mL}$ across treatments.

Situations of diet-induced MFD are often correlated with enhanced levels of trans 18:1 FA in milk fat (Davis and Brown, 1970; Bauman and Griinari, 2003); the role of specific trans 18:1 isomers in the regulation of milk fat synthesis, however, has not been examined extensively. In the current study, the infusion of EA and VA

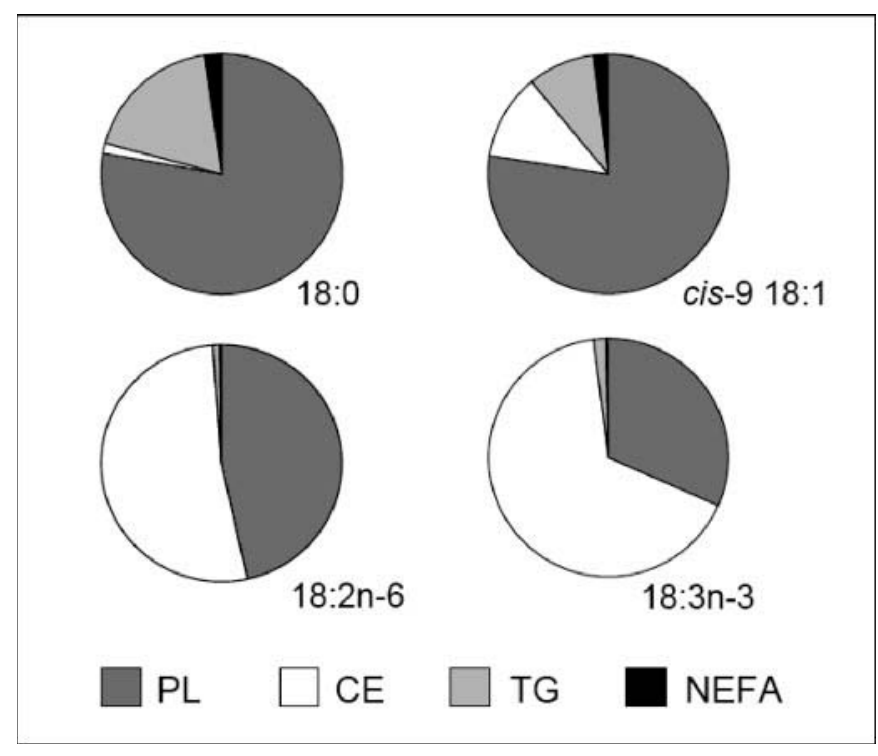

Figure 1. Plasma distribution of 18:0 and 18-carbon cis double bond-containing fatty acids at baseline (pretreatment values; based on total concentration of individual isomers in plasma). Fatty acids 18:0, cis-9 18:1, 18:2n-6, and 18:3n-3 accounted (mean \pm SEM) for $13.4 \pm 0.4 \%, 6.4 \pm 0.3 \%, 41.7 \pm 0.8 \%$, and $6.0 \pm 0.1 \%$ of total plasma fatty acids at baseline. Abbreviations for plasma lipid fractions: $\mathrm{PL}=$ phospholipids, $\mathrm{CE}=$ cholesterol esters, $\mathrm{TG}=$ triglycerides.

had no effect on milk fat yield or content. In the study by Lock et al. (2007), we similarly demonstrated that abomasal infusion of trans-10 18:1 at $45 \mathrm{~g} / \mathrm{d}$, did not affect milk fat synthesis. Other investigations utilizing trans 18:1 isomers have also observed no effects on milk fat production for EA (25 g/d; Rindsig and Schultz, 1974) or VA and trans-12 18:1 in a 50:50 mixture (dose range 7.1 to 29.4 g/d; Griinari et al., 2000; Shingfield et al., 2007). Furthermore, an indirect examination of trans 18:1 isomers, by feeding cows approximately $500 \mathrm{~g} / \mathrm{d}$ of OA, resulted in a 1.7-fold increase in the milk fat content of total trans isomers (profile not specified), but had no effect on milk fat yield or content (Selner and Schultz, 1980). Overall, these studies provide no evidence for a causative role for specific trans 18:1 FA in diet-induced MFD. Nevertheless, changes in the content and profile of trans 18:1 isomers in milk fat may be a useful surrogate marker for changes in rumen fermentation associated with MFD (Lock et al., 2007; Shingfield and Griinari, 2007). Abomasal infusion of PHVO to dairy cows results in MFD, and this has been attributed to the high levels of trans-18:1 FA (Selner and Schultz, 1980; Gaynor et al., 1994; Romo et al., 1996). These results contrast with the lack of milk fat effects when pure trans-18:1 isomers have been investigated. Partially hydrogenated vegetable oil contains a Gaussian distribution of trans-18:1 isomers (approximately 40 to $60 \%$ of total FA), and not all trans-18:1 isomers have 
Table 5. Fatty acid composition of plasma phospholipid fraction on d 4 of infusion ${ }^{1}$

\begin{tabular}{|c|c|c|c|c|c|}
\hline \multirow[b]{2}{*}{ Fatty acid, g/100 g } & \multicolumn{3}{|c|}{ Fatty acid infusion ${ }^{2}$} & \multirow[b]{2}{*}{ SEM } & \multirow[b]{2}{*}{$P$-value ${ }^{3}$} \\
\hline & $\mathrm{OA}$ & EA & VA & & \\
\hline $14: 0$ & 1.04 & 1.00 & 1.03 & 0.10 & 0.69 \\
\hline $14: 1$, cis-9 & 0.32 & 0.29 & 0.33 & 0.02 & 0.35 \\
\hline $15: 0$ & 0.37 & 0.35 & 0.36 & 0.02 & 0.75 \\
\hline $16: 0$ & 12.44 & 11.87 & 12.07 & 0.41 & 0.31 \\
\hline $16: 1, c i s-9$ & 0.70 & 0.71 & 0.69 & 0.04 & 0.39 \\
\hline $17: 0$ & 1.25 & 1.24 & 1.25 & 0.04 & 0.90 \\
\hline $18: 0$ & $23.28^{\mathrm{a}}$ & $23.28^{\mathrm{a}}$ & $22.87^{\mathrm{b}}$ & 0.41 & 0.02 \\
\hline $18: 1$, total trans & $1.65^{\mathrm{c}}$ & $2.63^{\mathrm{a}}$ & $2.35^{\mathrm{b}}$ & 0.03 & $<0.001$ \\
\hline $18: 1$, trans -4 & 0.05 & 0.05 & 0.06 & 0.03 & 0.50 \\
\hline $18: 1$, trans -5 & 0.03 & 0.03 & 0.03 & 0.01 & 0.98 \\
\hline $18: 1$, trans $-6-8$ & 0.11 & 0.07 & 0.12 & 0.02 & 0.44 \\
\hline $18: 1$, trans -9 & $0.17^{\mathrm{b}}$ & $1.22^{\mathrm{a}}$ & $0.14^{\mathrm{b}}$ & 0.03 & $<0.001$ \\
\hline $18: 1$, trans -10 & 0.13 & 0.13 & 0.10 & 0.01 & 0.25 \\
\hline $18: 1$, trans -11 & $0.68^{\mathrm{b}}$ & $0.64^{\mathrm{b}}$ & $1.35^{\mathrm{a}}$ & 0.04 & $<0.001$ \\
\hline 18:1, trans-12 & 0.53 & 0.49 & 0.54 & 0.02 & 0.21 \\
\hline $18: 1, c i s-9$ & $11.03^{\mathrm{ab}}$ & $12.20^{\mathrm{a}}$ & $10.37^{\mathrm{b}}$ & 0.63 & 0.02 \\
\hline $18: 2 n-6$ & 22.44 & 23.52 & 24.09 & 1.05 & 0.19 \\
\hline $20: 0$ & 0.07 & 0.06 & 0.06 & 0.00 & 0.09 \\
\hline $18: 3 n-6$ & 0.19 & 0.24 & 0.23 & 0.03 & 0.18 \\
\hline $18: 3 n-3$ & 1.62 & 2.08 & 2.05 & 0.11 & 0.17 \\
\hline $18: 2$, cis -9, trans -11 & 0.08 & 0.08 & 0.12 & 0.01 & 0.07 \\
\hline $20: 3 n-6$ & 3.97 & 4.01 & 4.11 & 0.22 & 0.59 \\
\hline $20: 4 n-6$ & 2.66 & 2.96 & 2.96 & 0.20 & 0.38 \\
\hline $23: 0$ & 0.33 & 0.24 & 0.29 & 0.07 & 0.39 \\
\hline $20: 5 n-3$ & 0.48 & 0.53 & 0.58 & 0.05 & 0.06 \\
\hline $24: 0$ & 0.25 & 0.23 & 0.22 & 0.04 & 0.72 \\
\hline $22: 4 n-6$ & 0.58 & 0.61 & 0.60 & 0.04 & 0.76 \\
\hline $22: 5 n-3$ & 0.89 & 0.96 & 0.97 & 0.07 & 0.57 \\
\hline $22: 6 n-3$ & 0.06 & 0.06 & 0.06 & 0.01 & 0.12 \\
\hline Other & 12.28 & 12.21 & 12.69 & 0.55 & 0.30 \\
\hline
\end{tabular}

been tested for effects on milk fat production; however, the hydrogenation process also results in the formation of several conjugated and other unique FA isomers that are present in PHVO, and some of these could regulate milk fat synthesis [see discussion in Lock et al. (2007) and reviews by Bauman and Griinari (2003) and Shingfield and Griinari (2007)].

\section{Plasma Lipid Fractions and Treatment Effects}

Baseline (pretreatment) concentrations of the individual plasma lipid fractions and the FA content of these plasma fractions are presented in Table 4 . These values are in agreement with those typically seen for mature cattle in late lactation (Christie, 1981). The proportions of total plasma FA associated with each lipid fraction at baseline were $62.6 \pm 0.6 \%, 26.1 \pm 0.6 \%$, $9.8 \pm 0.4 \%$, and $1.5 \pm 0.1 \%$ for PL, CE, TG, and NEFA, respectively.
The FA composition of the individual plasma lipid fractions at baseline was strikingly different. For plasma PL, the FA with the greatest content were linoleic acid $(18: 2 \mathrm{n}-6 ; 23.3 \%)$ and stearic acid (18:0, $22.8 \%)$, followed by palmitic acid $(16: 0,12.3 \%)$ and OA $(9.9 \%)$. For the plasma CE fraction, linoleic acid was the predominant FA, accounting for $61.8 \%$ of total FA, followed by linolenic acid (18:3n-3; 10.2\%). Stearic acid was the major FA in plasma TG, accounting for 39.3\% of the FA, followed by palmitic acid (20.5\%) and OA (11.6\%). The FA composition of the NEFA fraction was similar to plasma TG, with the major FA components being stearic acid (44.4\%), palmitic acid (16.5\%), and OA (11.6\%).

Quantitatively, across all fractions, the distribution of individual FA isomers at baseline varied with chain length and degree of unsaturation. Palmitic acid accounted for $8.8 \pm 0.2 \%$ of total plasma FA, and its plasma distribution was $67.4 \% \mathrm{PL}, 9.9 \% \mathrm{CE}, 19.3 \% \mathrm{TG}$, and $3.4 \%$ NEFA (data not shown). The distribution of 
TYBURCZY ET AL.

Table 6. Fatty acid composition of plasma cholesterol ester fraction on d 4 of infusion ${ }^{1}$

\begin{tabular}{|c|c|c|c|c|c|}
\hline \multirow[b]{2}{*}{ Fatty acid, g/100 g } & \multicolumn{3}{|c|}{ Fatty acid infusion ${ }^{2}$} & \multirow[b]{2}{*}{ SEM } & \multirow[b]{2}{*}{$P$-value ${ }^{3}$} \\
\hline & OA & EA & VA & & \\
\hline $14: 0$ & 0.71 & 0.71 & 0.64 & 0.09 & 0.65 \\
\hline $14: 1$, cis -9 & 1.04 & 1.12 & 1.12 & 0.04 & 0.15 \\
\hline $15: 0$ & 0.67 & 0.68 & 0.69 & 0.03 & 0.18 \\
\hline $16: 0$ & 4.00 & 4.07 & 4.04 & 0.08 & 0.27 \\
\hline $16: 1$, cis -9 & 1.06 & 1.15 & 1.12 & 0.07 & 0.19 \\
\hline $17: 0$ & $0.22^{\mathrm{b}}$ & $0.30^{\mathrm{a}}$ & $0.30^{\mathrm{a}}$ & 0.02 & 0.04 \\
\hline $18: 0$ & 0.68 & 0.67 & 0.66 & 0.10 & 0.21 \\
\hline $18: 1$, total trans & 0.26 & 0.27 & 0.29 & 0.02 & 0.49 \\
\hline $18: 1$, trans -4 & 0.00 & 0.00 & 0.00 & 0.00 & 1.00 \\
\hline $18: 1$, trans -5 & 0.00 & 0.00 & 0.00 & 0.00 & 1.00 \\
\hline $18: 1$, trans $-6-8$ & 0.01 & 0.00 & 0.02 & 0.00 & 0.08 \\
\hline 18:1, trans -9 & 0.02 & 0.04 & 0.03 & 0.01 & 0.56 \\
\hline $18: 1$, trans -10 & 0.03 & 0.03 & 0.03 & 0.01 & 0.97 \\
\hline $18: 1$, trans -11 & 0.06 & 0.05 & 0.07 & 0.01 & 0.11 \\
\hline $18: 1$, trans-12 & 0.14 & 0.14 & 0.15 & 0.02 & 0.65 \\
\hline $18: 1$, cis-9 & 3.82 & 3.81 & 3.59 & 0.33 & 0.30 \\
\hline $18: 2 n-6$ & 64.30 & 63.44 & 62.78 & 0.85 & 0.06 \\
\hline $20: 0$ & 0.06 & 0.03 & 0.04 & 0.01 & 0.09 \\
\hline $18: 3 n-6$ & 2.08 & 2.10 & 2.14 & 0.11 & 0.81 \\
\hline $18: 3 n-3$ & 10.38 & 10.63 & 10.69 & 0.39 & 0.64 \\
\hline $18: 2$, cis -9, trans -11 & 0.05 & 0.05 & 0.06 & 0.01 & 0.21 \\
\hline $20: 3 n-6$ & 0.66 & 0.65 & 0.76 & 0.06 & 0.39 \\
\hline $20: 4 n-6$ & 1.70 & 1.66 & 1.65 & 0.06 & 0.23 \\
\hline 23:0 & 0.01 & 0.01 & 0.02 & 0.01 & 0.24 \\
\hline $20: 5 n-3$ & 0.77 & 0.76 & 0.84 & 0.11 & 0.77 \\
\hline $24: 0$ & 0.01 & 0.00 & 0.10 & 0.03 & 0.10 \\
\hline $22: 4 n-6$ & 0.00 & 0.00 & 0.00 & 0.00 & 0.98 \\
\hline $22: 5 n-3$ & 0.06 & 0.02 & 0.02 & 0.02 & 0.28 \\
\hline $22: 6 n-3$ & 0.00 & 0.00 & 0.01 & 0.01 & 0.44 \\
\hline Other & $7.45^{\mathrm{b}}$ & $7.66^{\mathrm{b}}$ & $8.43^{\mathrm{a}}$ & 0.35 & 0.02 \\
\hline
\end{tabular}

18-carbon FA is presented in Figure 1. Stearic acid accounted for $13.4 \pm 0.4 \%$ of total plasma FA at baseline, and its distribution was $77.9 \% \mathrm{PL}, 1.2 \% \mathrm{CE}, 18.8 \% \mathrm{TG}$, and $2.1 \%$ NEFA. Oleic acid accounted for $6.4 \pm 0.3 \%$ of total plasma FA and was distributed $77.3 \%$ to PL, $11.5 \%$ to CE, $9.1 \%$ to TG, and $2.1 \%$ to NEFA. Linoleic acid accounted for $41.7 \pm 0.8 \%$ of total plasma FA, and its distribution among plasma lipid fractions was 46.8 , $52.0,0.9$, and $0.2 \%$ for PL, CE, TG, and NEFA, respectively. Linolenic acid accounted for $6.0 \pm 0.1 \%$ of total plasma FA, and its plasma distribution was $31.7 \%$ PL, 66.3\% CE, 1.7\% TG, and 0.3\% NEFA. In contrast, the long-chain PUFA, eicosapentaenoic acid (20:5n3 ) and docosahexaenoic acid (22:6n-3), together with their intermediate metabolite, docosapentaenoic acid (22:5n-3), accounted for less than $2 \%$ of total plasma FA; more than $95 \%$ of these isomers were distributed in the plasma PL and CE fractions (data not shown). Thus, it is apparent that with an increasing number of cis double bonds, there are major shifts in the pattern of distribution such that more of the FA is distributed to the plasma CE fraction, with concomitant decreases in plasma PL and TG (Figure 1).

On $d 4$ of the treatment periods, the proportion of circulating FA in the different plasma fractions was similar to baseline values, averaging $59.7 \pm 0.9 \%, 28.0$ $\pm 0.7 \%, 11.2 \pm 0.4 \%$, and $1.2 \pm 0.1 \%$ for PL, CE, TG, and NEFA, respectively. Infusion of trans-18:1 isomers resulted in increases in the total lipid concentration for plasma CE, TG, and free cholesterol, as compared with values observed during the OA infusion (Table 5).

The major effect of treatment on plasma FA was to cause a specific increase in the content of infused isomers in the various plasma lipid fractions. The plasma PL fraction was most affected by treatment (Table 5), whereas plasma CE was least affected (Table 6). For plasma PL, there was nearly a 7 -fold increase of EA and a doubling of VA in the respective FA infusions. The plasma PL content of OA was intermediate for the OA treatment relative to the other 2 treatments. For 
Table 7. Fatty acid distribution of plasma triglyceride fraction on d 4 of infusion ${ }^{1}$

\begin{tabular}{|c|c|c|c|c|c|}
\hline \multirow[b]{2}{*}{ Fatty acid, g/100 g } & \multicolumn{3}{|c|}{ Fatty acid infusion ${ }^{2}$} & \multirow[b]{2}{*}{ SEM } & \multirow[b]{2}{*}{$P$-value ${ }^{3}$} \\
\hline & $\mathrm{OA}$ & EA & VA & & \\
\hline $14: 0$ & 1.35 & 1.74 & 1.51 & 0.28 & 0.44 \\
\hline $14: 1$, cis -9 & 0.85 & 0.97 & 0.87 & 0.08 & 0.15 \\
\hline $15: 0$ & 1.08 & 1.17 & 1.15 & 0.07 & 0.26 \\
\hline $16: 0$ & 20.55 & 20.92 & 20.54 & 0.89 & 0.88 \\
\hline $16: 1$, cis -9 & 0.79 & 0.88 & 0.88 & 0.09 & 0.40 \\
\hline $17: 0$ & 1.10 & 1.11 & 1.12 & 0.07 & 0.95 \\
\hline $18: 0$ & $43.23^{\mathrm{a}}$ & $39.88^{b}$ & $39.30^{\mathrm{b}}$ & 2.18 & 0.04 \\
\hline $18: 1$, total trans & 4.64 & 5.75 & 7.47 & 0.53 & 0.09 \\
\hline $18: 1$, trans -4 & 0.07 & 0.05 & 0.07 & 0.02 & 0.43 \\
\hline $18: 1$, trans -5 & 0.07 & 0.04 & 0.05 & 0.02 & 0.43 \\
\hline $18: 1$, trans $-6-8$ & $0.55^{\mathrm{a}}$ & $0.44^{\mathrm{b}}$ & $0.51^{\mathrm{a}}$ & 0.02 & 0.02 \\
\hline $18: 1$, trans -9 & $0.39^{\mathrm{b}}$ & $1.50^{\mathrm{a}}$ & $0.33^{\mathrm{b}}$ & 0.21 & 0.01 \\
\hline $18: 1$, trans -10 & 0.54 & 0.64 & 0.53 & 0.03 & 0.24 \\
\hline $18: 1$, trans -11 & $2.34^{\mathrm{b}}$ & $2.38^{\mathrm{b}}$ & $5.13^{\mathrm{a}}$ & 0.48 & 0.03 \\
\hline $18: 1$, trans -12 & 0.93 & 0.71 & 0.84 & 0.08 & 0.20 \\
\hline $18: 1, c i s-9$ & $8.88^{\mathrm{a}}$ & $8.56^{\mathrm{a}}$ & $8.01^{b}$ & 0.30 & 0.03 \\
\hline $18: 2 n-6$ & 2.42 & 2.24 & 2.66 & 0.46 & 0.57 \\
\hline $20: 0$ & 0.55 & 0.64 & 0.50 & 0.10 & 0.43 \\
\hline $18: 3 n-6$ & 0.00 & 0.00 & 0.00 & 0.00 & 1.00 \\
\hline $18: 3 n-3$ & 0.66 & 0.57 & 0.64 & 0.12 & 0.82 \\
\hline $18: 2$, cis -9, trans -11 & 0.03 & 0.10 & 0.12 & 0.05 & 0.42 \\
\hline $20: 3 n-6$ & 0.11 & 0.23 & 0.09 & 0.11 & 0.45 \\
\hline $20: 4 n-6$ & 0.00 & 0.00 & 0.00 & 0.00 & 1.00 \\
\hline $23: 0$ & 0.18 & 0.29 & 0.22 & 0.04 & 0.09 \\
\hline $20: 5 n-3$ & 0.00 & 0.00 & 0.00 & 0.00 & 1.00 \\
\hline $24: 0$ & 0.30 & 0.28 & 0.27 & 0.02 & 0.15 \\
\hline $22: 4 n-6$ & 0.08 & 0.02 & 0.02 & 0.01 & 0.30 \\
\hline $22: 5 n-3$ & 0.17 & 0.13 & 0.08 & 0.04 & 0.32 \\
\hline $22: 6 n-3$ & 0.00 & 0.00 & 0.00 & 0.00 & 1.00 \\
\hline Other & 13.24 & 14.29 & 14.32 & 1.17 & 0.63 \\
\hline
\end{tabular}

plasma TG, there was a 3 -fold increase of EA and a doubling of VA in the respective infusions (Table 7). The content of OA in plasma TG did not differ between the EA and OA treatments, but was lower for the VA treatment. For plasma NEFA, there was a 4 - to 5 -fold increase of EA and an 80 to $100 \%$ increase of VA in the respective infusions; however, the content of OA was unaffected by treatment (Table 8). We observed that infusion of EA and VA had little effect on the content of the infused FA in the plasma CE fraction (Table 6). This contrasts with Offer et al. (2001), who reported increases of trans 18:1 isomers in plasma CE, but not plasma TG, in dairy cows after consuming $300 \mathrm{~g} / \mathrm{d}$ of fish oil.

The infused trans isomers appeared to be taken up well by the plasma PL, TG, and NEFA fractions, although differences among fractions existed. For example, there was a 7 -fold increase of EA in the PL fraction, and less of an increase of EA in the plasma TG and NEFA fractions. A preferential incorporation of EA in plasma PL has been demonstrated previously, and may be a consequence of the modest incorporation of EA in plasma CE (Coots, 1964). With regard to VA, previous studies have demonstrated a preferential distribution to plasma TG in lactating dairy cows (Loor et al., 2002) and humans (Innis and King, 1999; Shahin et al., 2006). On the other hand, Mosley et al. (2006) found that across all fractions, the amount of VA was greatest in the plasma PL of lactating dairy cows. In the present study, we observed a doubling of VA in both the PL and TG fractions, and this suggests that differences among studies most likely relate to the absolute concentration of FA in the PL and TG fractions.

The unique distribution of FA among plasma lipid fractions is one example of the body's ability to recognize and allocate FA differentially for specific metabolic purposes. For example, in the current study, $59 \%$ of total linoleic acid and $74 \%$ of total linolenic acid were distributed to the plasma CE fraction. These FA have been shown to be good substrates for lecithin-choles- 
TYBURCZY ET AL.

Table 8. Fatty acid distribution of plasma nonesterified fatty acid fraction on d 4 of infusion ${ }^{1}$

\begin{tabular}{|c|c|c|c|c|c|}
\hline \multirow[b]{2}{*}{ Fatty acid, g/100 g } & \multicolumn{3}{|c|}{ Fatty acid infusion ${ }^{2}$} & \multirow[b]{2}{*}{ SEM } & \multirow[b]{2}{*}{$P$-value ${ }^{3}$} \\
\hline & $\mathrm{OA}$ & $\mathrm{EA}$ & VA & & \\
\hline $14: 0$ & 0.68 & 0.91 & 1.20 & 0.19 & 0.13 \\
\hline $14: 1$, cis -9 & 0.33 & 0.40 & 0.41 & 0.05 & 0.22 \\
\hline $15: 0$ & 0.42 & 0.51 & 0.57 & 0.08 & 0.24 \\
\hline $16: 0$ & 15.58 & 16.37 & 17.46 & 1.00 & 0.37 \\
\hline $16: 1$, cis-9 & 0.79 & 0.92 & 0.94 & 0.05 & 0.13 \\
\hline $17: 0$ & 1.05 & 1.06 & 1.11 & 0.09 & 0.88 \\
\hline $18: 0$ & 46.92 & 44.18 & 43.84 & 2.56 & 0.54 \\
\hline $18: 1$, total trans & 4.14 & 4.59 & 5.47 & 0.60 & 0.31 \\
\hline $18: 1$, trans -4 & 0.00 & 0.00 & 0.00 & 0.00 & 1.00 \\
\hline $18: 1$, trans -5 & 0.00 & 0.00 & 0.00 & 0.00 & 1.00 \\
\hline $18: 1$, trans $-6-8$ & 0.36 & 0.18 & 0.18 & 0.10 & 0.44 \\
\hline $18: 1$, trans -9 & $0.24^{\mathrm{b}}$ & $1.39^{\mathrm{a}}$ & $0.34^{\mathrm{b}}$ & 0.09 & 0.04 \\
\hline $18: 1$, trans -10 & 0.75 & 0.77 & 0.75 & 0.12 & 0.98 \\
\hline $18: 1$, trans -11 & $1.98^{\mathrm{a}}$ & $1.67^{\mathrm{a}}$ & $3.49^{b}$ & 0.33 & 0.02 \\
\hline $18: 1$, trans -12 & 0.72 & 0.58 & 0.72 & 0.22 & 0.79 \\
\hline $18: 1$, cis -9 & 12.03 & 10.86 & 12.15 & 0.83 & 0.34 \\
\hline $18: 2 n-6$ & 5.59 & 5.63 & 6.28 & 0.72 & 0.23 \\
\hline $20: 0$ & 0.59 & 0.59 & 0.49 & 0.05 & 0.21 \\
\hline $18: 3 n-6$ & 0.00 & 0.00 & 0.00 & 0.00 & 1.00 \\
\hline $18: 3 n-3$ & 0.65 & 0.83 & 0.67 & 0.10 & 0.51 \\
\hline $18: 2$, cis -9, trans -11 & 0.00 & 0.05 & 0.07 & 0.07 & 0.70 \\
\hline $20: 3 n-6$ & 0.00 & 0.00 & 0.39 & 0.16 & 0.28 \\
\hline $20: 4 n-6$ & 0.36 & 0.27 & 0.14 & 0.30 & 0.81 \\
\hline $23: 0$ & 0.64 & 0.67 & 0.13 & 0.11 & 0.07 \\
\hline $20: 5 n-3$ & 0.00 & 0.00 & 0.00 & 0.00 & 1.00 \\
\hline $24: 0$ & 0.80 & 1.08 & 0.75 & 0.13 & 0.12 \\
\hline $22: 4 n-6$ & 0.17 & 0.00 & 0.00 & 0.07 & 0.28 \\
\hline $22: 5 n-3$ & 0.29 & 0.18 & 0.07 & 0.07 & 0.27 \\
\hline $22: 6 n-3$ & 0.00 & 0.00 & 0.00 & 0.00 & 1.00 \\
\hline Other & 10.25 & 8.07 & 8.15 & 1.25 & 0.46 \\
\hline
\end{tabular}

terol acyltransferase, the enzyme involved in plasma CE formation (Jonas, 1986). On the other hand, stearic acid and trans 18:1 FA are less preferred substrates for lecithin-cholesterol acyltransferase, and this may explain the modest incorporation of the infused EA and VA, as well as stearic acid, in the plasma CE fraction (Table 6).

\section{Milk FA Composition and Treatment Effects}

Treatments resulted in increases in the milk FA content of the specific isomers infused (Table 9). The infused FA progressively increased in milk fat content during the treatment period, and for the infused trans 18:1 FA, incorporation into milk fat reached an apparent plateau by d 3 to 4 (Figure 2). Milk FA content of EA increased from $0.33 \%$ of milk FA before infusion to $3.21 \%$ on $\mathrm{d} 3$ to 4 of the EA infusion. Milk fat concentration of OA averaged $22.74 \%$ of milk FA before treatment and increased to $25.27 \%$ by d 3 to 4 of the
OA infusion. For the VA infusion, there was a 1.5 -fold increase in the concentrations of both VA and RA in milk fat, and the ratio of VA to RA remained unaffected and averaged $2.8 \pm 0.1$ over the 4 -d infusion period. This increase of RA in milk fat is consistent with the endogenous conversion of VA to RA via the mammary enzyme $\Delta^{9}$-desaturase (Bauman and Lock, 2006).

After correcting for endogenous levels in milk fat, the transfer efficiency of infused OA and EA to milk fat averaged $65.5 \pm 3.0 \%$ and $59.7 \pm 1.5 \%$, respectively. Transfer of infused VA to milk fat averaged of $54.3 \pm$ $0.6 \%$, of which $24.6 \pm 1.1 \%$ was accounted for by the increased yield of RA in milk fat. A similarly high rate of transfer is often seen for FA that are taken up well by the mammary gland, including stearic, oleic, and palmitic acids (Wu et al., 1993; LaCount et al., 1994). However, as the chain length and number of double bonds increases, transfer efficiency to milk fat decreases. As reviewed by Lock and Bauman (2004), the transfer of abomasally infused eicosapentaenoic acid 
Table 9. Fatty acid composition of milk fat in response to infusion of the treatment fatty acids ${ }^{1}$

\begin{tabular}{|c|c|c|c|c|c|}
\hline \multirow[b]{2}{*}{ Fatty acid, g/100 g } & \multicolumn{3}{|c|}{ Fatty acid infusion ${ }^{2}$} & \multirow[b]{2}{*}{ SEM } & \multirow[b]{2}{*}{$P$-value } \\
\hline & $\mathrm{OA}$ & EA & VA & & \\
\hline $4: 0$ & 3.96 & 3.96 & 3.91 & 0.19 & 0.31 \\
\hline $6: 0$ & 2.11 & 2.07 & 2.13 & 0.04 & 0.47 \\
\hline $8: 0$ & 1.12 & 1.09 & 1.16 & 0.04 & 0.42 \\
\hline $10: 0$ & 2.31 & 2.20 & 2.45 & 0.12 & 0.25 \\
\hline $12: 0$ & 2.60 & 2.51 & 2.79 & 0.15 & 0.25 \\
\hline $14: 0$ & $9.85^{\mathrm{b}}$ & $10.02^{\mathrm{a}}$ & $10.22^{\mathrm{a}}$ & 0.29 & 0.04 \\
\hline $14: 1$, cis -9 & 0.90 & 1.07 & 0.95 & 0.21 & 0.15 \\
\hline $15: 0$ & 0.85 & 0.84 & 0.90 & 0.04 & 0.17 \\
\hline $16: 0$ & 28.39 & 28.81 & 28.78 & 1.77 & 0.93 \\
\hline $16: 1$, cis -9 & 1.46 & 1.55 & 1.40 & 0.15 & 0.10 \\
\hline $17: 0$ & $0.54^{\mathrm{a}}$ & $0.51^{b}$ & $0.55^{\mathrm{a}}$ & 0.01 & 0.05 \\
\hline $18: 0$ & 11.63 & 10.83 & 11.60 & 0.39 & 0.38 \\
\hline $18: 1$, total trans & $2.93^{\mathrm{c}}$ & $5.77^{\mathrm{a}}$ & $4.71^{\mathrm{b}}$ & 0.21 & 0.02 \\
\hline $18: 1$, trans -4 & 0.02 & 0.02 & 0.02 & 0.00 & 0.45 \\
\hline $18: 1$, trans -5 & 0.02 & 0.01 & 0.02 & 0.00 & 0.06 \\
\hline $18: 1$, trans $-6-8$ & $0.31^{\mathrm{a}}$ & $0.22^{\mathrm{b}}$ & $0.30^{\mathrm{a}}$ & 0.01 & 0.02 \\
\hline $18: 1$, trans -9 & $0.39^{\mathrm{b}}$ & $3.21^{\mathrm{a}}$ & $0.27^{\mathrm{b}}$ & 0.04 & $<0.001$ \\
\hline $18: 1$, trans -10 & 0.40 & 0.47 & 0.35 & 0.05 & 0.26 \\
\hline $18: 1$, trans -11 & $1.26^{\mathrm{b}}$ & $1.32^{\mathrm{b}}$ & $3.20^{\mathrm{a}}$ & 0.21 & 0.005 \\
\hline $18: 1$, trans-12 & 0.53 & 0.52 & 0.57 & 0.02 & 0.23 \\
\hline $18: 1$, cis -9 & $25.27^{\mathrm{a}}$ & $22.85^{\mathrm{b}}$ & $21.70^{\mathrm{b}}$ & 1.09 & 0.03 \\
\hline $18: 2 n-6$ & 2.20 & 1.98 & 2.13 & 0.07 & 0.12 \\
\hline $20: 0$ & 0.10 & 0.10 & 0.10 & 0.01 & 0.65 \\
\hline $18: 3 n-3$ & 0.40 & 0.37 & 0.39 & 0.01 & 0.30 \\
\hline $18: 2$, cis- 9, trans -11 & $0.48^{b}$ & $0.52^{\mathrm{b}}$ & $1.11^{\mathrm{a}}$ & 0.06 & $<0.001$ \\
\hline Other & 2.90 & 2.96 & 3.02 & 0.05 & 0.25 \\
\hline
\end{tabular}

and docosahexaenoic acid to milk fat is much lower, averaging approximately 20 to $30 \%$.

Reports on the transfer efficiency of individual trans 18:1 isomers to milk fat are limited to only a few studies. We recently demonstrated a $15 \%$ transfer of abomasally infused trans-10 18:1 to milk fat, and postulated that this low transfer efficiency may be due to inefficient absorption at the small intestine or the fact that this trans isomer may be metabolized differently in the body (Lock et al., 2007). Griinari et al. (2000) demonstrated that $40 \%$ of abomasally infused VA and $64 \%$ of infused trans-12 18:1 were transferred to milk fat, with 31 and $10 \%$, respectively, of the transfer being accounted for by increases in yield of the $\Delta^{9}$-desaturation products of the infused isomers (RA and cis-9, trans-12 18:2, respectively). Shingfield et al. (2007) reported comparatively lower transfer efficiencies for VA and trans-12 18:1 (29 and 34\%, respectively), with 8 and $2 \%$, respectively, of the transfer being accounted for by the increased yield of the $\Delta^{9}$-desaturation products.

Measurements on the arteriovenous difference of FA across the mammary gland have been useful for investigating the extraction of FA from various plasma lipid fractions for milk fat synthesis. Glascock et al. (1966) demonstrated that plasma TG provide the main source of FA taken up by the bovine mammary gland, and these results were confirmed by Annison et al. (1967) in lactating goats. Annison et al. (1967) also observed there was little net uptake of FA from the NEFA pool; however, the use of labeled FA enabled the authors to demonstrate significant mammary extraction of labeled NEFA, with concomitant release of unlabeled NEFA. Plasma PL and CE are generally not considered major suppliers of FA for mammary uptake, although some studies suggest a modest contribution of FA from the plasma PL fraction for milk fat synthesis (Glascock et al., 1966; Christie et al., 1986; Nielsen and Jakobsen, 1994).

Consistent with the preferential mammary uptake of FA from plasma TG and NEFA, the long-chain FA composition of milk fat from cows in the current study most closely mimicked the composition of FA in the plasma TG and NEFA fractions. On the other hand, plasma PL and CE contained several long-chain PUFA, branchedchain FA, and alcohols not observed in milk fat (data not shown), indicating that these FA may not be taken 


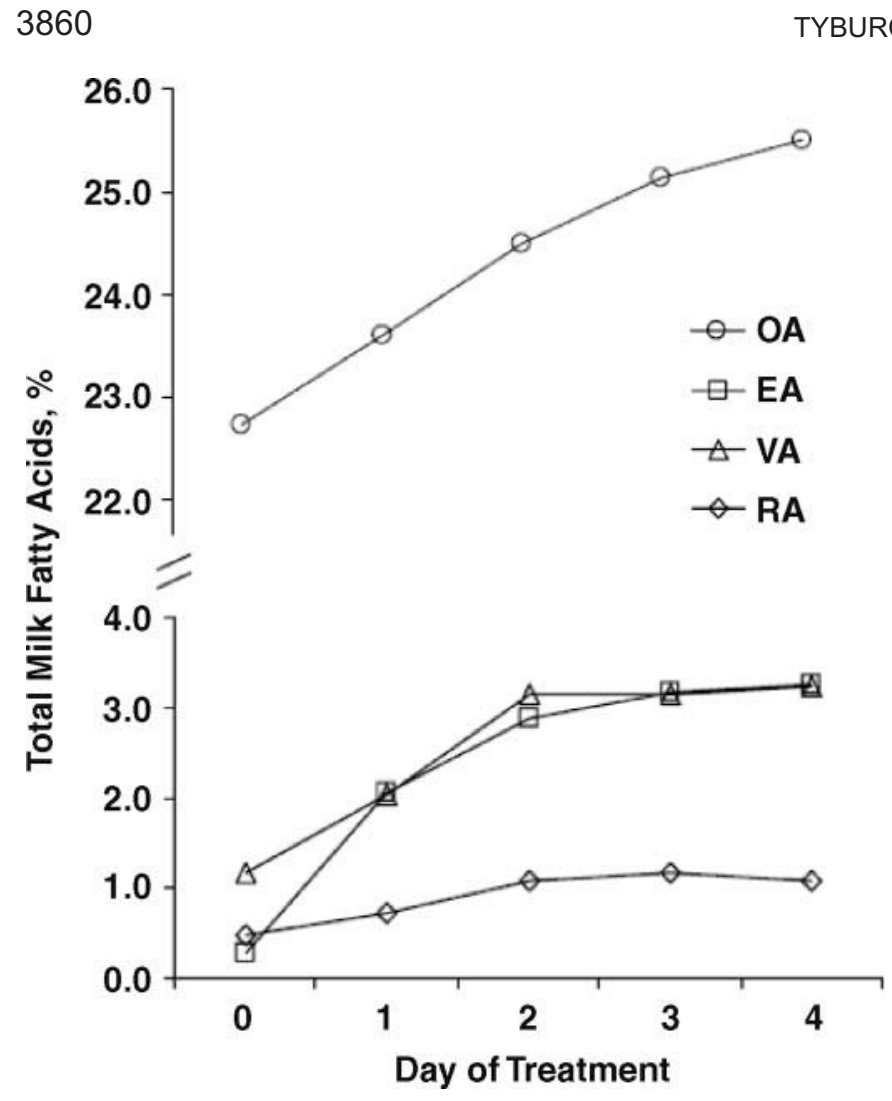

Figure 2. Temporal incorporation of infused isomers, cis-9 18:1 (OA), trans-9 18:1 (EA), and trans-11 18:1 (VA) in milk fatty acids over the 4-d infusion period. For the VA treatment, the milk fat content of cis-9, trans-11 18:2 (rumenic acid; RA) progressively increased. Values represent means from 3 cows; SEM averaged 1.11, $0.04,0.12$, and 0.04 for OA, EA, VA, and RA, respectively, over the treatment period.

up well by the mammary gland, or that plasma PL or CE may be less well utilized as a source of FA for mammary uptake. Most notably, we observed that linoleic and linolenic acids constituted approximately $47.7 \%$ of the total FA in plasma, but only approximately $2.6 \%$ of the FA in milk fat. The differences between plasma and milk fat appear to relate to the distribution of these FA predominantly in plasma PL and CE, plasma lipid fractions that are less well utilized for mammary uptake and that have a low turnover rate (Moore and Christie, 1979; Noble, 1984). However, when the supply of linoleic and linolenic acids is increased by abomasal infusion, there is good transfer to milk fat (e.g., $53 \%$ for 18:2; LaCount et al., 1994), suggesting that in this situation, FA may be transported in plasma fractions more available for use by the mammary gland (e.g., TG or NEFA); additional research will be needed to examine this possibility more completely. Furthermore, as originally suggested by Noble (1984), FA predominantly distributed to plasma CE and PL may have specific biological functions (e.g., synthesis of essential FA and signaling molecules, cell membrane structure) that necessitate their preservation within plasma, whereas FA distributed to plasma TG and NEFA may play a more general role in lipid metabolism (e.g., energy source, fat storage, milk fat synthesis).

In conclusion, OA, EA, and VA were taken up by the mammary gland and secreted in milk fat at a high rate of transfer; treatment, however, had no effect on milk fat yield or content. For the VA infusion, there was an increase of RA in milk lipids, consistent with the endogenous conversion of VA to RA via the mammary enzyme $\Delta^{9}$-desaturase. Infusion of the treatment isomers resulted in their specific increase in the various plasma lipid fractions, with plasma PL being most affected and plasma CE least affected. Distribution of 18-carbon FA among plasma lipid fractions was particularly striking, especially for the longer chain PUFA that were predominantly associated with the plasma PL and CE fractions. Thus, results demonstrate there are clear differences in the plasma transport and mammary uptake and utilization of 18-carbon FA, and this relates to the location, orientation, and number of double bonds.

\section{ACKNOWLEDGMENTS}

The authors would like to acknowledge the support and assistance of G. Birdsall, J. T. Brenna, E. Castañeda-Gutiérrez, L. Furman, K. J. Harvatine, B. Johnson, W. Jones, P. Lawrence, A. M. O’Donnell, D. Parr, and S. Stachnich.

\section{REFERENCES}

Allison, D. B., M. A. Denke, J. M. Dietschy, E. A. Emken, P. M. KrisEtherton, and R. J. Nicolosi. 1995. Trans fatty acids and coronary heart disease risk. Report of the expert panel on trans fatty acids and coronary heart disease. Am. J. Clin. Nutr. 62:655S-708S.

Annison, E. F., J. L. Linzell, S. Fazakerley, and B. W. Nichols. 1967. The oxidation and utilization of palmitate, stearate, oleate and acetate by the mammary gland of the fed goat in relation to their overall metabolism, and the role of plasma phospholipids and neutral lipids in milk-fat synthesis. Biochem. J. 102:637-647.

Bauman, D. E., and J. M. Griinari. 2003. Nutritional regulation of milk fat synthesis. Annu. Rev. Nutr. 23:203-227.

Bauman, D. E., and A. L. Lock. 2006. Conjugated linoleic acid: Biosynthesis and nutritional significant. Pages 93-136 in Advanced Dairy Chemistry. Volume 2: Lipids. P. F. Fox and P. L. H. Sweeney, ed. Springer, New York, NY.

Bernal-Santos, G., J. W. Perfield, D. M. Barbano, D. E. Bauman, and T. R. Overton. 2003. Production responses of dairy cows to dietary supplementation with conjugated linoleic acid (CLA) during the transition period and early lactation. J. Dairy Sci. 86:3218-3228.

Chouinard, P. Y., L. Corneau, D. M. Barbano, L. E. Metzger, and D. E. Bauman. 1999. Conjugated linoleic acids alter milk fatty acid composition and inhibit milk fat secretion in dairy cows. J. Nutr. 129:1579-1584.

Christie, W. W. 1981. The composition, structure and function of lipids in the tissues of ruminant animals. Pages 95-191 in Lipid 
Metabolism in Ruminant Animals. W. W. Christie, ed. Pergamon Press Inc., Elmsford, NY.

Christie, W. W. 1982. A simple procedure for rapid transmethylation of glycerolipids and cholesteryl esters. J. Lipid Res. 23:10721075 .

Christie, W. W. 1989. Gas Chromatography and Lipids: A Practical Guide. The Oily Press, Ayr, Scotland.

Christie, W. W., R. C. Noble, and R. A. Clegg. 1986. The hydrolysis of very low density lipoproteins and chylomicrons of intestinal origin by lipoprotein lipase in ruminants. Lipids 21:252-253.

Coots, R. H. 1964. A comparison of the metabolism of elaidic, oleic, palmitic, and stearic acids in the rat. J. Lipid Res. 5:468-472.

Davis, C. L., and R. E. Brown. 1970. Low-fat milk syndrome. Pages 545-565 in Physiology of Digestion and Metabolism in the Ruminant. A. T. Phillipson, ed. Oriel Press, Newcastle upon Tyne, UK

Fox, D. G., L. O. Tedeschi, T. P. Tylutki, J. B. Russell, M. E. Van Amburgh, L. E. Chase, A. N. Pell, and T. R. Overton. 2004. The Cornell Net Carbohydrate and Protein System model for evaluating herd nutrition and nutrient excretion. Anim. Feed Sci. Technol. 112:29-78.

Gaynor, P. J., R. A. Erdman, B. B. Teter, J. Sampugna, A. V. Capuco, D. R. Waldo, and M. Hamosh. 1994. Milk fat yield and composition during abomasal infusion of cis or trans octadecenoates in Holstein cows. J. Dairy Sci. 77:157-165.

Glascock, R. F., V. A. Welch, C. Bishop, T. Davies, E. W. Wright, and R. C. Noble. 1966. An investigation of serum lipoproteins and of their contribution to milk fat in the dairy cow. Biochem. J. 98:149-156

Glasser, F., M. Doreau, A. Ferlay, and Y. Chilliard. 2007. Technical note: Estimation of milk fatty acid yield from milk fat data. J. Dairy Sci. 90:2302-2304.

Griinari, J. M., B. A. Corl, S. H. Lacy, P. Y. Chouinard, K. V. V. Nurmela, and D. E. Bauman. 2000. Conjugated linoleic acid is synthesized endogenously in lactating dairy cows by $\Delta^{9}$. desaturase. J. Nutr. 130:2285-2291.

Hara, A., and N. S. Radin. 1978. Lipid extraction of tissues with a low-toxicity solvent. Anal. Biochem. 90:420-426.

Innis, S. M., and D. J. King. 1999. Trans fatty acids in human milk are inversely associated with concentrations of essential all-cis n-6 and n-3 fatty acids and determine trans, but not n- 6 and n-3, fatty acids in plasma lipids of breast-fed infants. Am. J. Clin. Nutr. 70:383-390.

Jonas, A. 1986. Synthetic substrates of lecithin: Cholesterol acyltransferase. J. Lipid Res. 27:689-698.

LaCount, D. W., J. K. Drackley, S. O. Laesch, and J. H. Clark. 1994. Secretion of oleic acid in milk fat in response to abomasal infusions of canola or high oleic sunflower fatty acids. J. Dairy Sci. 77:1372-1385.

Lock, A. L., and D. E. Bauman. 2004. Modifying milk fat composition of dairy cows to enhance fatty acids beneficial to human health. Lipids 39:1197-1206.

Lock, A. L., C. Tyburczy, D. A. Dwyer, K. J. Harvatine, F. Destaillats, Z. Mouloungui, L. Candy, and D. E. Bauman. 2007. Trans-10 octadecenoic acid does not reduce milk fat synthesis in dairy cows. J. Nutr. 137:71-76.

Loor, J. J., J. H. Herbein, and C. E. Polan. 2002. Trans 18:1 and 18:2 isomers in blood plasma and milk fat of grazing cows fed a grain supplement containing solvent-extracted or mechanically extracted soybean meal. J. Dairy Sci. 85:1197-1207.
Loor, J. J., K. Ueda, A. Ferlay, Y. Chilliard, and M. Doreau. 2004. Biohydrogenation, duodenal flow, and intestinal digestibility of trans fatty acids and conjugated linoleic acids in response to dietary forage:concentrate ratio and linseed oil in dairy cows. J. Dairy Sci. 87:2472-2485.

Moore, J. H., and W. W. Christie. 1979. Lipid metabolism in the mammary gland of ruminant animals. Prog. Lipid Res. 17:347395.

Mosley, E. E., B. Shafi, P. J. Moate, and M. A. McGuire. 2006. Cis9 , trans-11 conjugated linoleic acid is synthesized directly from vaccenic acid in lactating dairy cattle. J. Nutr. 136:570-575.

NRC. 2001. Nutrient Requirements of Dairy Cattle. 7th rev. ed. Natl. Acad. Sci., Washington, DC.

Nielsen, M. O., and K. Jakobsen. 1994. Changes in mammary uptake of free fatty acids, triglyceride, cholesterol and phospholipid in relation to milk synthesis during lactation in goats. Comp. Biochem. Physiol. 109A:857-867.

Noble, R. C. 1984. Essential fatty acids in the ruminant. Pages 185200 in Fats in Animal Nutrition. J. Wiseman, ed. Butterworths, London, UK.

Offer, N. W., B. K. Speake, J. Dixon, and M. Marsden. 2001. Effect of fish-oil supplementation on levels of (n-3) poly-unsaturated fatty acids in the lipoprotein fractions of bovine plasma. Anim. Sci. 73:523-531

Palmquist, D. L., A. L. Lock, K. J. Shingfield, and D. E. Bauman. 2005. Biosynthesis of conjugated linoleic acid in ruminants and humans. Pages 179-218 in Advances in Food and Nutrition Research. Vol. 50. S. L. Taylor, ed. Elsevier Inc., San Diego, CA.

Perfield, J. W. II, G. Bernal-Santos, T. R. Overton, and D. E. Bauman. 2002. Effects of dietary supplementation of rumen-protected conjugated linoleic acid in dairy cows during established lactation. J. Dairy Sci. 85:2609-2617.

Rindsig, R. B., and L. H. Schultz. 1974. Effects of abomasal infusions of safflower oil or elaidic acid on blood lipids and milk fat in dairy cows. J. Dairy Sci. 57:1459-1466.

Romo, G. A., D. P. Casper, R. A. Erdman, and B. B. Teter. 1996 Abomasal infusion of cis or trans fatty acid isomers and energy metabolism of lactating dairy cows. J. Dairy Sci. 79:2005-2015.

Selner, D. R., and L. H. Schultz. 1980. Effects of feeding oleic acid or hydrogenated vegetable oils to lactating cows. J. Dairy Sci. 63:1235-1241.

Shahin, A. M., M. K. McGuire, N. Anderson, J. Williams, and M. A. McGuire. 2006. Effects of margarine and butter composition on distribution of trans-18:1 fatty acid isomers and conjugated linoleic acid in major serum lipid classes in lactating women. Lipids 41:141-147.

Shingfield, K. J., S. Ahvenjärvi, V. Toivonen, A. Vanhatalo, and P. Huhtanen. 2007. Transfer of absorbed cis-9, trans-11 conjugated linoleic acid into milk is biologically more efficient than endogenous synthesis from absorbed vaccenic acid in lactating cows. J. Nutr. 137:1154-1160.

Shingfield, K. J., and J. M. Griinari. 2007. Role of biohydrogenation intermediates in milk fat depression. Eur. J. Lipid Sci. Technol. 109:799-816.

Willett, W. C. 2006. Trans fatty acids and cardiovascular diseaseEpidemiological data. Atheroscler. Suppl. 7:5-8.

Wu, Z., J. T. Huber, F. T. Sleiman, J. M. Simas, K. H. Chen, S. C. Chan, and C. Fontes. 1993. Effect of three supplemental fat sources on lactation and digestion in dairy cows. J. Dairy Sci. $76: 3562-3570$. 